\title{
Professor Da-Wen Sun Conferred with Honorary Doctorate Degree from Peru
}

Wilson Castro $^{1}$

Published online: 24 February 2018

(C) Springer Science+Business Media, LLC, part of Springer Nature 2018
Professor Da-Wen Sun, from UCD School of Biosystems and Food Engineering, has been conferred with Honorary Doctorate Degree from the Universidad Privada del Norte (UPN) in Peru in recognition of his exceptional contribution and leading role for advancing food and biosystems engineering research and education at the global level. A special conferring ceremony was held on 12 February 2018 in the Breña Campus of UPN in Lima. Dr. Andrés Velarde, the Rector of UPN, presented Professor Sun with the certificate, medal and plaque of the honorary doctorate of UPN (Fig. 1).

In his conferring speech, Dr. Andrés Velarde said that this was the first honorary doctorate he has conferred during his rectorship in the past 7 years; he hoped that this honour would further strengthen the collaboration between Professor Sun and UPN and helps uplift the quality and reputation of UPN at international level.

Speaking for accepting the honour during the event, Professor Sun said it was a great honour for him to have received an honorary doctorate from UPN, "I really appreciate UPN for conferring this honorary doctorate degree upon me today. I will forever hold it with pride and humility and allow it to serve as a testament to the value of serving our profession with commitment and compassion"; "I understand that accepting this distinction is not only a great honour, but also a responsibility

Wilson Castro

wilson.castro@upn.edu.pe

1 Facultad de Ingeniería, Universidad Privada del Norte, 06002 Cajamarca, Cajamarca, Peru to me. The honorary doctorate degree from UPN provides me an opportunity, a platform and a communication channel for furthering our effective collaboration."

UPN, established by the Peruvian Congress Law $\mathrm{N}^{\circ}$ 26275 in November 1993, is the first international university in northern Peru. The university has six campuses in Trujillo and Cajamarca and Lima, with a total student population of over 60,000 . Since September 2007, UPN has become a member of Laureate International Universities and has quickly developed an outstanding reputation for the quality of its teaching and scholarship, and for its pluralistic and global outlook. According to the latest ranking of uniRank ${ }^{\mathrm{TM}}$ based in Australia, UPN is ranked No. 10 in about 150 universities in Peru, and based on QS World University Rankings, UPN is among the best in Latin America.

Professor Sun is a world authority in food engineering research and education. His many scholarly works have become standard reference materials for researchers in the areas of computer vision/hyperspectral imaging, computational fluid dynamics modelling, vacuum cooling, etc. Results of his work have been published in more than 500 peer-reviewed journal papers (Web of Science hindex $=86$, SCOPUS h-index $=90$ ) with 39 papers being designated by ESI as highly cited papers. He is the recipient of numerous awards and honours including election to the Royal Irish Academy in 2010, selection as a Member of Academia Europaea (The Academy of Europe) in 2011, induction as a Fellow of International Academy of Food Science and Technology in 2012, award as a Fellow of International Academy of Agricultural and Biosystems Engineering in 2016, and election as a Foreign Member of Polish Academy of Sciences in 2017. Among other international recognitions, 
Fig. 1 Dr. Andrés Velarde, the Rector of UPN, presented

Professor Sun with the certificate, medal and plaque of the honorary doctorate of UPN

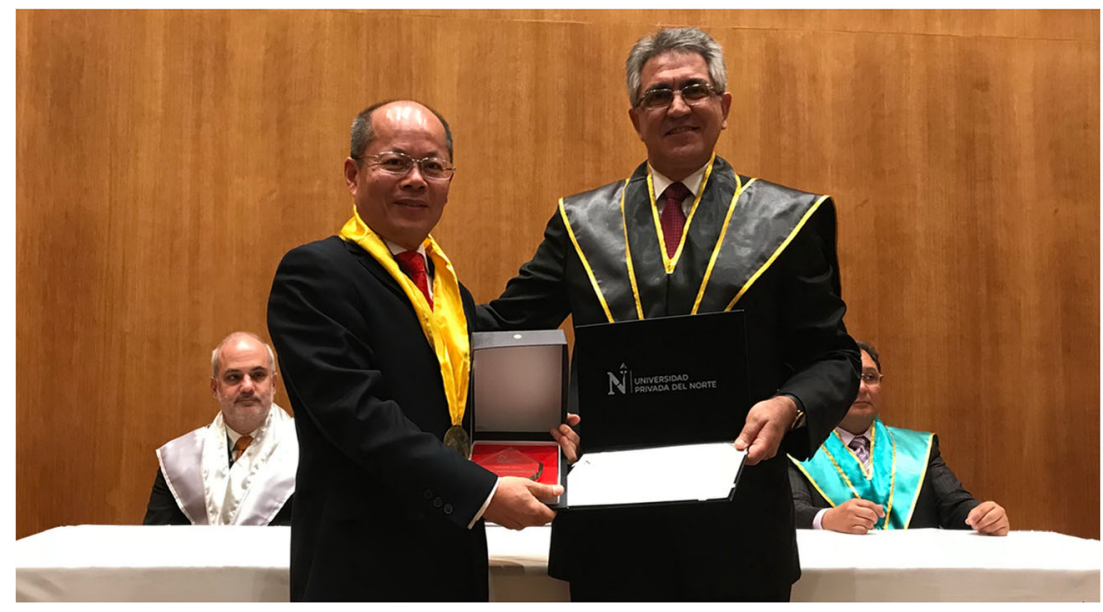

Professor Sun was the recipient of the CIGR Fellow Award in 2010, the Freezing Research Award in 2013 from the International Association for Food Protection (IAFP) and the IAEF Lifetime Achievement Award in 2015 from the International Association of Engineering and Food (IAEF). He has also been honoured as one of the "Highly Cited Researchers" in the last 3 consecutive years (2015-2017) by Clarivate Analytics (formerly Thomson Reuters). Professor Sun is also the founder and Editor in Chief of Food and Bioprocess Technology, one of the top food science and technology journals in the world. 